\title{
A PERCEPÇÃO DO PROFESSOR DO ATENDIMENTO EDUCACIONAL ESPECIALIZADO SOBRE SEU PAPEL NA INCLUSÃO ESCOLAR
}

\author{
PERCEPCIÓN DEL PROFESOR DEL PROFESOR DE CUIDADO EDUCATIVO \\ ESPECIALIZADO SOBRE SU PAPEL EN LA INCLUSIÓN ESCOLAR
}

\author{
TEACHER'S PERCEPTION OF SPECIALIZED EDUCATIONAL CARE TEACHER \\ ABOUT YOUR ROLE IN SCHOOL INCLUSION
}

\author{
Josiane Fujisawa FILUS DE FREITAS ${ }^{1}$ \\ Paulo FERREIRA DE ARAÚJO
}

\begin{abstract}
RESUMO: Este estudo teve como objetivo identificar a percepção dos professores do AEE sobre seu papel na organização da inclusão escolar em um município. Participaram de nossa investigação 17 professoras, todas com formação em Pedagogia e pós-graduação Lato Sensu em Educação Especial. Utilizando como recurso metodológico a análise de conteúdo, percebemos que os conceitos das professoras de AEE consideram sua atuação mais voltada ao atendimento individualizado do aluno, a fim de melhorar seu desempenho escolar. Constatamos que a organização do município permitiu a incorporação dessa função, visto que o atendimento é itinerante com o objetivo de levar até o aluno aquilo que ele teria na escola especial. Concluímos que o professor do AEE necessita se sentir parte da escola, ser presença constante para fornecer os conhecimentos necessários da Educação Especial para a escola regular, efetivando as ações inclusivas com os professores.
\end{abstract}

PALAVRAS-CHAVE: Atendimento Educacional Especializado. Inclusão Escolar. Educação Especial.

RESUMEN: Este estudio tuvo como objetivo identificar la percepción de los maestros de la ESA sobre su papel en la organización de la inclusión escolar en un municipio. Diecisiete maestros, todos entrenados en Pedagogía y posgrado de Lato Sensu en Educación Especial, participaron en nuestra investigación. Utilizando el análisis de contenido como recurso metodológico, nos damos cuenta de que los conceptos de los docentes de la ESA consideran que su desempeño está más centrado en la atención individualizada del alumno, a fin de mejorar su desempeño escolar. Descubrimos que la organización del municipio permitió la incorporación de esta función, ya que el servicio es itinerante para llevar al estudiante lo que tendría en la escuela especial. Concluimos que el maestro de ESA necesita sentirse parte de la escuela, ser una presencia constante para proporcionar el conocimiento necesario de Educación Especial para la escuela regular, efectuando acciones inclusivas con los maestros.

PALABRAS CLAVE: Atención educativa especializada. Inclusión escolar. Educación especial.

${ }^{1}$ Universidade Federal da Grande Dourados (UFGD), Dourados - MS - Brasil. Professora da Faculdade de Educação. ORCID: https://orcid.org/0000-0002-0282-7007. E-mail: josianefffreitas@ufgd.edu.br

${ }^{2}$ Universidade Estadual de Campinas (UNICAMP), Campinas - SP - Brasil. Professor da Faculdade de Educação Física. ORCID: https://orcid.org/0000-0001-7805-578X. E-mail: paulof@fef.unicamp.br 
ABSTRACT: This study aimed to identify the perception of Specialized Educational Service teachers about their role in the organization of educational inclusion in a municipality. Seventeen teachers participated in our research, all with a background in Pedagogy and a Lato Sensu postgraduate in Special Education. Using as a methodological resource the content analysis we perceive that the concepts of the SES teachers consider their performance more focused on the individualized attendance of the student, in order to improve their school performance. We verified that the organization of the municipality allowed the incorporation of this function, since the attendance is itinerant with the objective of taking to the student what he would have in the special school. We conclude that the ESA teacher needs to feel part of the school, to be a constant presence to provide the necessary knowledge of Special Education to the regular school, carrying out the inclusive actions together with the teachers.

KEYWORDS: Specialized Educational Service. Educational Inclusion. Especial Education.

\section{Introdução}

A presença do professor especialista em Educação Especial é fundamental para o trabalho inclusivo nas escolas. Os municípios têm se adequado para compor esse quadro e prover o atendimento especializado às crianças com deficiência, no entanto o processo inclusivo ainda demanda muitas reflexões, visto que a presença desses profissionais não garante por si só a efetivação da inclusão, pois é um trabalho de todo o coletivo escolar.

Compreendemos o conceito de inclusão a partir dos estudos e reflexões de Mantoan (2004), o qual é entendido como o entrelaçamento das diferenças humanas, o contato e o compartilhamento de singularidades. Esse conceito emerge da complexidade e, portanto, traz a necessidade de reforma do pensamento e da escola, de modo que sejam capazes de ministrar uma educação plural, democrática e transgressora. Esse movimento abala a identidade institucional e a dos professores e faz com que seja ressignificada a identidade do aluno (MANTOAN, 2004).

Nesse sentido, torna-se importante compreender a visão dos profissionais do Atendimento Educacional Especializado (AEE) sobre sua presença e participação na escola pois esse grupo é recente na escola e teve que adequar sua atuação no decorrer da implantação do processo inclusivo.

O presente texto traz uma breve fundamentação teórica sobre a inclusão escolar e os vários atores desse processo, dando destaque aos especialistas em AEE. A pesquisa de campo contou com a participação do grupo de professores atuantes no serviço de AEE do município de Hortolândia-SP.

Desse modo, o objetivo deste estudo foi identificar a percepção dos professores do AEE sobre seu papel na organização da inclusão escolar em um município do Estado de São 
Paulo. O foco na forma de organização de um município possibilita-nos refletir sobre uma realidade específica e ampliar essa análise para outros contextos.

\section{Fundamentação Teórica}

A escola inclusiva exige de todos um novo posicionamento e uma nova forma de trabalho, baseada num trabalho efetivamente coletivo. Um exemplo dessa nova maneira de perceber as relações visando à inclusão escolar pode ser identificado na pesquisa de Garcez (2004) que, por meio da pesquisa-ação, participou das horas de trabalho coletivo dos professores de uma escola pública municipal e, com um planejamento composto por leitura de textos e discussões coletivas, auxiliou o grupo de professores na elaboração de Projetos de Inclusão. A pesquisadora apontou, no início do trabalho, que uma dúvida comum dos professores era sobre o encaminhamento; eles alertavam para sua a falta de preparo para atender a alguns casos. Muitos professores reivindicavam a presença de um especialista para auxiliar nesse processo. Ouvindo constantemente essas reclamações, a pesquisadora percebeu que muitos professores têm dificuldade na identificação dos alunos que apresentam "problemas" geradores de encaminhamento para atendimento especializado. Nesse contexto, um profissional especializado, da área da saúde, teria a incumbência de sanar todos os problemas, atendendo aqueles casos mais difíceis, incluídos nesse grupo aqueles alunos que, por inúmeras razões, nem sempre objetivadas, eram passíveis de um tipo "sutil" de exclusão escolar.

Sobre o ato de diagnosticar e a presença do professor especialista, Tomasini (1998) levanta os dois lados da moeda: se, por um lado, localiza o indivíduo, indicando o tipo de terapêutica a ser posta em circulação, por outro, pode funcionar como um limite nas expectativas sobre suas verdadeiras potencialidades. O diagnóstico da deficiência fixa o indivíduo como se estivesse parado no tempo, ficando muito difícil mudar a situação na qual foi enquadrado. Assim, como professores, não lhe damos a palavra, não lhe perguntamos o que quer ou não, o que precisa e o que realmente lhe interessa. Seu saber é desqualificado, considerado não competente ou insuficientemente elaborado: saber ingênuo, hierarquicamente inferior, abaixo do nível requerido de conhecimento ou de cientificidade (TOMASINI, 1998).

Trata-se de um aspecto preocupante, principalmente quando encontramos estudos como o de Denari (2006), que destaca que, atualmente, tem ocorrido um maciço encaminhamento indevido aos serviços de Educação Especial, de alunos defasados em relação idade/série, encaminhamento respaldado, muitas vezes, por avaliações incompletas, discutíveis, sem que esses alunos sejam necessariamente deficientes. 
Enfocando o trabalho da professora especialista em Educação Especial, Moreira (2006) analisou o ensino itinerante de Educação Especial do município de Araraquara-SP, onde tais professoras têm dias e horários agendados para atendimento dos alunos com deficiência incluídos no ensino regular, assim como horário de orientações com as professoras desses alunos. Após um ano de acompanhamento do trabalho, a pesquisadora observou que o ensino itinerante, apesar de possuir intersecção com o ensino comum, ainda não está plenamente definido na escola comum, sua identidade e importância ainda estão em construção, pois, apesar de dividir espaço com o ensino comum, são dois sistemas paralelos, o que sinaliza um hiato entre ambos, comprometendo a dinâmica desse serviço de apoio. Ela relata que a possibilidade de junção entre ambos aparece em momentos de crise do ensino comum, em que o ensino itinerante se apresenta como solução à falta de respostas do ensino comum.

A autora percebeu ainda que a professora itinerante, muitas vezes, precisava ficar contatando as outras professoras para os agendamentos, mas sabe-se que o ideal seria que o interesse em agendar reuniões com a professora itinerante partisse também das professoras do ensino comum. Por esse fato, as conversas eram realizadas rapidamente, muitas vezes na porta da sala de aula, não sendo possível analisar mais detalhes referentes aos atendimentos dos alunos.

Essa estrutura faz com que não ocorra de modo satisfatório o intercâmbio entre o ensino comum e o especial, cristalizando a separação entre ambos. Esse fator compromete sensivelmente a dinâmica de funcionamento desse serviço, que deveria atuar de forma mais integrada, de modo a fundir esses dois sistemas num único na perspectiva de fortalecer a escola inclusiva almejada para o futuro. Isso é bem observado nos relatos da pesquisadora (MOREIRA, 2006, p. 198):

Devido à dificuldade de conexão, e de diálogo entre estes dois sistemas, há problemas de interpretação da função do ensino itinerante, e assim, as professoras do ensino comum avaliam, do ponto de vista da autora do presente trabalho, equivocadamente, que os alunos são de responsabilidade da professora do ensino itinerante, que, além de atender os alunos, organizar o material pedagógico, indicar recursos, ainda oferece dicas de como trabalhar com os alunos na sala de aula comum. Em razão desta postura dinâmica da professora do ensino itinerante, convencionou-se, por parte das professoras do ensino comum, certo conforto com relação ao aluno inserido em sua classe, e por tal razão, assumem uma postura mais passiva frente à educação deste aluno. Mas pode-se dizer também que o grau de comprometimento das professoras frente aos alunos inseridos varia conforme a dedicação e o envolvimento de cada uma delas.

Portanto, as professoras do ensino comum deixam de aproveitar a oportunidade de aprender mais sobre o como fazer no processo de inclusão, pois esse sistema de apoio não é 
visto pelas professoras da rede como uma possibilidade de capacitação em serviço. Esse dado pode ser confirmado pelas significativas ausências ou os constantes "esquecimentos" detectados no cotidiano da escola sobre as reuniões mensais entre a professora do ensino comum e a professora itinerante, nas quais muitas dúvidas poderiam ser sanadas, muitas dicas poderiam ser sugeridas, muitas atividades poderiam ser propostas e textos informativos poderiam ser indicados, pois seriam fundamentais para a mobilização e estruturação de concepções básicas ao processo inclusivo (MOREIRA, 2006).

No entanto, no decorrer das entrevistas com as professoras, elas sinalizam que o ensino itinerante é um ótimo recurso existente na escola. Assim, pode-se notar que, no campo discursivo, o ensino itinerante é apontado como solução, embora no tocante à sua aplicação prática perceba-se a necessidade de este se efetivar a contento, pois as professoras relatam também um sentimento de solidão muito acentuado. Cabe ressaltar ainda que na fala das professoras do ensino comum há uma percepção relacionada com a sincronia temporal, que marca a diferença temporal entre o ensino comum e o ensino especial e assim descrevem que existem ritmos diferentes entre ambos e que elas são pressionadas pelo tempo e pela necessidade de resultados a curto prazo.

A fim de sugerir melhores maneiras de aliar ensino comum e especial, a autora coloca a necessidade de oportunizar às professoras do ensino comum um momento de maior reflexão, no qual se percebessem como fundamentais ao processo de inclusão, já que elas não se deslocam na inter-relação entre os dois ensinos e não se colocam como mediadoras entre o serviço de itinerância prestado pela professora e os alunos por ele atendidos. Coloca ainda questões para refletir sobre essa estrutura: Será que o desafio para o ensino itinerante não seria levar as intervenções para a sala de aula? Haveria assim maior contribuição por parte do especialista se este estivesse trabalhando com a professora do ensino comum, e não apenas com as crianças separadamente? Será que há real compatibilidade entre os currículos do ensino comum e do ensino especial? Não seria esse mais um fator agravante? Será que uma proposta fundamentada no ensino colaborativo não atenuaria a situação atual?

A dificuldade na relação Ensino Comum x Especial é destacada por Denari (2006) como foco da formação profissional das especialistas, em que aponta que seria desejável que: ocorresse em nível superior; a parte específica seja alicerçada sobre uma base comum, assegurando que esse profissional, antes de tudo, seja um professor; a parte específica vise a atuação entre o professor de educação especial e o professor do ensino comum, centrando o apoio no âmbito da classe comum. Essa prática também deve ser buscada entre todos os professores, pois ambos os contextos estão historicamente acostumados a caminhar separadamente, porém, agora, devem encontrar formas para se relacionarem. Além da 
formação profissional, os termos da lei como "clientela da Educação Especial” promovem entre os demais educadores a conotação de um modelo médico-psicológico e a ideia de uma pedagogia terapêutica, designações que precisam ser superadas a fim de auxiliar na aproximação entre essas duas modalidades de educação.

Acreditamos, portanto, que as dificuldades têm surgido nesse momento atual em que as crianças com deficiência estão presentes nas salas de aula e, portanto, não se tem uma "receita" de como trabalhar com a inclusão. Como todo processo, as resoluções dos problemas vêm surgindo à medida que se encontra solução para as questões, e, como estamos lidando com pessoas, cada uma delas tem suas particularidades, o que inviabiliza um roteiro de trabalho em que se encaixem as expectativas e soluções em todos os ambientes.

Outro núcleo importante de todo esse processo é a família. Para ela, a inclusão também é um momento novo e assustador. Luiz (2009), analisando a inclusão de crianças com Síndrome de Down na perspectiva de suas famílias, evidenciou a necessidade de seu acompanhamento antes, durante e após a inclusão propriamente dita, apoiando as crianças nos momentos de busca e escolha da escola, adaptação da criança ao novo ambiente e da transição dos atendimentos oferecidos pela instituição especializada para outros setores. Verificou ainda a necessidade de articulação entre os setores educacional e da saúde, além de um investimento e preparo das escolas e seus recursos humanos para a recepção dessa clientela.

Uma informação importante obtida com os familiares foi sobre o início do ano letivo. A maioria deles contou que todo início de ano acontece uma nova inclusão, pois, com a mudança de professora ou mesmo de escola, a família tem que fazer reuniões com a nova professora, passar informações e, assim, todo ano a expectativa é a mesma de quando a criança entrou na escola pela primeira vez. Para a pesquisadora, isso poderia ser sanado se os gestores da escola se envolvessem nesse processo captando as informações necessárias sobre a criança, estimulando os demais professores a se inteirar do caso.

Além disso, Luiz (2009) identificou como dificuldade para as famílias a falta de apoio da escola e órgãos como a prefeitura para estabelecer uma relação direta entre os profissionais da saúde e da educação, a fim de passar informações sobre as potencialidades da criança. Isso apenas aconteceu em alguns casos que possuíam fonoaudiólogas particulares, as quais ligavam para as professoras a fim de auxiliar no início da inclusão.

Apesar de as mães entrevistadas acreditarem que os professores não estão preparados para a inclusão, todos relataram que as crianças tiveram ganhos com a inserção no ensino regular, como maior desenvolvimento da fala e da coordenação motora, ficaram mais independentes e sociáveis, além de se apresentarem mais tranquilas. Outro fator assinalado foi a convivência com crianças sem deficiência, o que, no dizer das mães, é um estímulo para o 
desenvolvimento, como podemos ver neste trecho: "Ele vê as outras crianças falando, cantando, fazendo as coisas $\mathrm{e}$ isso o estimula. Eu creio que tudo contribuiu pro desenvolvimento dele, porque ele tá sempre no meio de outras crianças" (LUIZ, 2009, p. 84).

No entanto, essa satisfação não se repetiu com três famílias quando passaram a frequentar o ensino fundamental. Assim, corre-se o risco de o processo de inclusão ser bemsucedido apenas nas escolas de educação infantil, onde se prioriza a interação, e não a competência acadêmica, dando a conotação de que a inclusão é muito mais uma prática social do que formadora acadêmica. Portanto, cabe aos órgãos públicos propiciar condições às escolas regulares para atenderem corretamente essa população.

D’Água (2007) também constatou a dificuldade do processo no avanço dos estudos da criança, na passagem do Ensino Fundamental Ciclo I para Ciclo II e Ensino Médio. Ela destaca que a presença do professor especialista deve ser mantida e sua atuação acentuada nessa passagem, uma vez que para a criança também há mudanças significativas, como o aumento e a rotatividade de professores, o que exige maiores trocas e conhecimentos sobre o aluno com necessidades especiais.

Nesse sentido, Carvalho (2000) ressalta a necessidade de ouvir mais a família dessa criança e estabelecer mecanismos de escuta permanente para assim poder avaliar constantemente o desenvolvimento desse aluno e saber proporcionar os meios adequados para que sua aprendizagem não seja pontualmente na escola, mas que seja constante e levada também para dentro de casa.

Ainda não encontramos muitas pesquisas com respostas para as diversas dúvidas geradas pela inclusão de crianças com deficiência no ensino comum. Como dito anteriormente, estamos iniciando um processo que no seu desenvolvimento proporciona a reflexão e atenção a pontos importantes, como por exemplo, atividades mais simples, diferenciadas do restante do conteúdo proposto para a turma, para os alunos com deficiência como recortes, colagens, ligar figuras, pintar no limite, treinar a coordenação motora.

Consideramos essa diferenciação como uma atitude excludente, que não favorece ao aluno um pleno desenvolvimento. Entretanto, esse quadro atual não é responsabilidade apenas do professor, mas, sim, resultado da organização dos serviços educacionais disponíveis na rede comum de ensino que, quando existem, muitas vezes carecem de uma rede de suporte que propicie a esse aluno não apenas sua inserção em ambientes comuns de ensino, mas a sua plena participação no cotidiano da sala de aula e da escola (OLIVEIRA, 2008a).

Em seus estudos, Briant (2008) identificou algumas estratégias utilizadas que partiram dos próprios professores: colocar os alunos em dupla, dar uma atividade diferente para o aluno com deficiência, utilizar materiais mais concretos para as atividades de matemática, 
tentar acionar a família para ajudar em casa com alguma tarefa específica. Os professores enfatizam que essas estratégias partem de tentativas, acertos e erros advindos de troca de experiências com outros colegas. Esse processo não é fácil; veja-se o sentimento de um professor entrevistado: “Às vezes não sei se estou fazendo certo. Muitas vezes tento fazer o mesmo que faço com os outros. E vou testando coisas diferentes, até acertar, e isso é angustiante" (BRIANT, 2008, p. 111).

Como uma sugestão para auxiliar o professor, a autora descreve a rede de apoio, composta por profissionais da saúde, e cita como exemplo o terapeuta ocupacional que pode dar suporte às discussões que envolvem uma reestruturação de atividades, das dinâmicas propostas em sala de aula, das possibilidades de participação dos alunos. Na prática, ele auxiliaria na remoção das barreiras arquitetônicas, confecção de materiais pedagógicos, troca de conhecimentos sobre as potencialidades do aluno. No entanto, como vimos, o trabalho conjunto dessa rede de apoio com os professores do ensino regular deve ser organizado para que não se torne um "passe de bola", deixando a responsabilidade para o outro.

Uma escola aberta à diversidade necessita de mudanças que serão decorrentes das particularidades e individualidades dos alunos. Nesse sentido, a adaptação curricular possibilita a prática docente mediante a reformulação das estratégias da ação pedagógica, objetivando o desempenho satisfatório do aluno na sua rotina escolar. Para isso, deve-se observar o aluno durante a realização de atividades, identificando sua função e disfunção, ou seja, suas limitações e suas possibilidades. Por exemplo, a modificação da preensão do lápis, por meio de ajustes no próprio objeto, possibilita o manuseio daqueles com problemas de coordenação motora fina, oferecendo condições motoras funcionais para o manuseio. “A normalidade ou anormalidade de alguém está, portanto, intimamente relacionada ao que se impõe como padrão de execução. Sendo assim, as necessidades educacionais da pessoa dependem também dos recursos convencionalmente utilizados" (ARAÚJO, 1998 apud DELMASSO; ARAÚJO, 2008, p. 70).

As adaptações curriculares são imprescindíveis nesse contexto, pois, a partir delas, todos os alunos terão oportunidade de demonstrar suas habilidades. Elas são estratégias educacionais que proporcionam aos alunos o acesso ao processo ensino-aprendizagem. $\mathrm{O}$ documento "Estratégias para a educação de alunos com necessidades educacionais especiais" (BRASIL, 2003) apresenta as adaptações curriculares divididas como de pequeno porte ou não significativas e as de grande porte ou significativas. As adequações curriculares são respostas educativas que devem ser dadas pelo sistema educacional para favorecer todos os alunos, possibilitando o acesso ao currículo, sua participação integral e o atendimento às necessidades educacionais especiais. As adequações significativas ou de grande porte 
envolvem ações de competência e atribuição das instâncias político-administrativas e dos sistemas de ensino de todos os âmbitos: municipal, estadual e federal; as não significativas ou de pequeno porte compreendem modificações menores, de competência específica do professor, uma vez que se concentram em ajustes no contexto da sala de aula (OLIVEIRA, 2008a).

Como as adaptações são modificações na forma de realização de tarefas, nos objetos de manuseio e nas estratégias de aprendizagem utilizadas para favorecer a experiência de todos, sua prescrição envolve questões sociais, pois o meio e as atividades nele praticados demandam funcionalidade dentro dos padrões de anormalidade.

Uma pessoa em cadeira de rodas poderá ter dificuldade para o uso dos espaços escolares ou mesmo para o uso de carteiras em seu desenho tradicional, sendo necessários ajustes nos limites do ambiente, da pessoa ou de ambos. Da mesma forma, uma criança, cuja capacidade funcional não lhe permita a manutenção do equilíbrio da posição sentada, dificilmente conseguirá permanecer na sala de aula sem modificações no mobiliário. Outra criança sem capacidade funcional para a preensão do lápis dificilmente conseguirá realizar a escrita sem a modificação das qualidades do caderno convencional e/ou sem a alteração da preensão do lápis (DELMASSO; ARAÚJO, 2008, p. 71).

Mudanças na maneira de realizar uma atividade ou de dispor os móveis ou utensílios no ambiente são adaptações. Pode-se também ajustar a demanda curricular (ritmo e conteúdo de aprendizagem) às capacidades intelectual, motora e/ou sensorial dos alunos. Por exemplo, podem-se modificar as regras do jogo de basquete para a participação de crianças com deficiência física ou visual. Também é indicada a modificação na distribuição das carteiras para melhor acomodar os alunos com deficiência.

Perante déficits da visão, da audição, de problemas motores e/ou cognitivos é preciso que se propicie a exploração do meio ou do objeto de manuseio previamente à realização da atividade. Isso requer ajuste no ritmo de execução, a fim de que a experiência seja completa. A administração do tempo é, portanto, um fator a ser considerado na atenção à criança com necessidades educacionais especiais (OLIVEIRA, 2008a, p. 71).

Carvalho (2000, p. 10) considera essas modificações como o "remover barreiras na prática pedagógica em sala de aula".

Para Del-Masso e Araújo (2008), é preciso identificar e analisar em que medida o meio ambiente favorece a discrepância de desempenho, tanto nos aspectos contextuais como na demanda de tarefas, pois a inclusão pressupõe atenção na relação entre habilidades e hábitos. Na rotina escolar, se a criança não demonstra habilidade, não conseguirá realizar a tarefa/hábito. No entanto, se os hábitos não forem padronizados, e, sim, se concretizarem em uma gama de atividades diferenciadas para se atingir um mesmo objetivo, cada criança poderá 
experimentar e descobrir sua habilidade para cada tarefa; nesse caso, não haverá criança sem vivenciar a atividade, pois todas conseguirão realizá-la a seu modo, de acordo com sua habilidade.

Nesse contexto, a indicação do ambiente segregado dar-se-ia quando o meio não dispõe de recursos que favoreçam a participação das pessoas com deficiência. Assim, a inclusão implica acessibilidade, ou seja, condição para uso dos espaços, mobiliários e equipamentos urbanos, das edificações, sistemas e meios de comunicação e informação por pessoas com deficiência. Nessa perspectiva, a concepção de ambiente facilitador da experiência deve se pautar por parâmetros ergonômicos na direção do desenho universal. O desenho universal é um modo de concepção de espaços e produtos visando a sua utilização pelo mais amplo espectro de usuários, incluindo pessoas de diferentes faixas etárias, pessoas que apresentem limitações funcionais temporárias ou permanentes, entre outros fatores que possam surgir (RIBEIRO, 2007). A meta do desenho universal é a segurança e o conforto para todos (DEL-MASSO; ARAÚJO, 2008).

Para Oliveira e Profeta (2008), a inclusão educacional está diretamente relacionada à aceitação da diversidade em sala de aula, mas, para sua real instauração, é necessária a reorganização pedagógica e administrativa da escola. Outrossim, a capacitação dos recursos humanos também se faz essencial, e sugere-se que o investimento nos professores deve acontecer com participação efetiva, diálogo, leitura de mundo, da realidade, identificação de qualidades, valorização da autonomia cultural, articulação entre teoria e prática, acreditando no aluno como cidadão do futuro e na educação como fator essencial para o seu desenvolvimento, como pudemos verificar em iniciativas de algumas pesquisas já citadas.

As adaptações curriculares são responsabilidade dos professores, porém não apenas deles. Para que se efetivem adaptações a contento é necessária uma rede de apoio à educação inclusiva, com a participação da direção escolar e demais gestores, professores da Educação Especial e outros profissionais, para a troca de experiências e reflexões sobre as melhores formas de adaptar os conteúdos curriculares. O que se tem percebido, a exemplo da inclusão de deficientes intelectuais na Educação Infantil, é apenas o acesso a conhecimentos de áreas como Brincadeiras e Artes, pois as adaptações não têm garantido o acesso desses alunos a conhecimentos referentes às áreas de Língua Portuguesa, Matemática, Natureza e Sociedade, para as quais as professoras julgam ser mais difícil propor alterações (ANTUNES, 2008).

Também diante dessa constatação, D’Água (2007, p. 132-133) selecionou as ações que parecem ser mais bem resolvidas de acordo com as necessidades específicas: 
- Quando falamos do Deficiente Visual, encontramos livros falados, comunicação escrita em Braille, softwares em uso e inúmeras pesquisas nessa área que buscam alunos/pessoas nos espaços sociais.

- Ao falarmos do Deficiente Auditivo ... a LIBRAS foi reconhecida pelo governo como a segunda língua nacional do país, e o intérprete tem sido destacado como figura essencial para a comunicação entre ouvintes e surdos.

- Quanto ao Deficiente Físico, em função dos avanços relativos à acessibilidade, atualmente podemos observar que os espaços públicos e privados têm se adequado a essas necessidades. Paralelamente, a tecnologia assistiva vem promover maior independência dos indivíduos.

- No entanto, ao discutirmos sobre a Deficiência Mental/Intelectual na perspectiva inclusiva, comumente nos deparamos com muita resistência.

Cada caso deve ser considerado de acordo com suas potencialidades para a inclusão. Omote (2008) chama-nos a atenção para a interpretação de alguns preceitos da educação inclusiva, como a ênfase na colocação de todas as crianças, sem exceção nenhuma, em classes de ensino comum, independentemente da natureza e do grau de comprometimento que possam apresentar. Para o autor, mesmo considerando os benefícios da oportunidade do convívio social, uma parcela de crianças e jovens, como aqueles com deficiência mental severa e profunda ou com deficiência múltipla, não tem possibilidade nenhuma de tirar proveito da inclusão em classe comum, pelo menos dentro das condições atuais de recursos didático-pedagógicos e de tratamento na área da saúde. O poder público local deve prover espaços e programas que favoreçam o convívio entre essas crianças e não delegar mais essa função à escola.

Retornando às experiências, Lustosa (2009) apresenta situações vivenciadas em sua pesquisa como uma reafirmação de que o paradigma da educação inclusiva é possível de se realizar. Em intervenção com professoras do Ensino Fundamental, de 2005 a 2008, implementou sistemáticas ações de formação e acompanhamento socioconstrutivista das práticas pedagógicas dos professores, sediada na perspectiva da ação-reflexão-ação. Os resultados da pesquisa evidenciaram que investimentos na reorganização do espaço escolar, no apoio pedagógico às professoras, nas ações de atenção às crianças e às suas especificidades, reverteram-se em melhor atendimento às necessidades e especificidades de ritmos, estilos de aprendizagem e de diferentes níveis conceituais dos alunos. No tocante às práticas pedagógicas, as principais mudanças localizaram-se nas formas de organização e gestão da classe, na proposição de atividades diversificadas e diferenciadas, na adoção da pedagogia de projetos e na implementação dos princípios da aprendizagem cooperativa. Essas mudanças produziram aulas mais significativas e criativas e uma maior autonomia e interação entre as crianças.

Para Lustosa (2009, p. 253-254), a construção de uma escola inclusiva requer mudanças na prática pedagógica, porém esta é interdependente da gestão da escola e do apoio 
à prática docente. As mudanças obtidas, relatadas a seguir, somente foram possíveis, pois houve o envolvimento e adesão de toda a organização escolar:

- Planejamento de atividades - concepção de aulas mais criativas e significativas; previsão de recursos, metodologias e apoios às atividades dos alunos com dificuldades, mantendo os mesmos objetivos e metas em trabalhos para a turma toda; elaboração de um plano de trabalho para a turma toda e para o aluno com deficiência, em particular (plano de intervenção baseado no estudo de caso do aluno, contendo metas, objetivos, formas de apoio, monitoramento da progressão das aprendizagens); planejamento de atividades, tendo como base o currículo da série em que atua, entre outros;

- Variedade dos métodos de ensino - adoção da Pedagogia de projetos; investimentos na diversificação dos métodos de ensino (aula expositiva, trabalhos concretos, experimentação, pesquisa, aulas de campo, debates e "cantos de atividades", trabalho em oficinas, laboratórios de aprendizagem etc.); exploração de aulas de campo, passeios e visitas a espaços da comunidade (mobilização de recursos da comunidade), entre outros;

- Estilos e ritmos dos alunos - proposição de atividades diversificadas voltadas aos diferentes "canais" de aprendizagem dos alunos a fim de atender aos distintos níveis conceituais; desenvolvimento de tarefas desafiadoras (atividades baseadas na proposição de conflitos sociocognitivos, resolução de situações-problema, sequência didática dos conteúdos/atividades desdobramentos, ou seja, de continuidade, com ampliação gradativa da complexidade, dentro do mesmo tema ou contexto); identificação e adoção de formas de apoio e tutorias, entre outros;

- Centros de interesse e iniciativa dos alunos - disponibilização das mais variadas formas de comunicação, priorizando atividades de acordo com as potencialidades do aluno; proposição de atividades em que o aluno faz sua opção de acordo com seus interesses, identificação das maiores habilidades/potencialidades do aluno, entre outros;

- Gestão da sala de aula - (re)configuração espacial da sala (formação de círculo ou semicírculo); implementação dos princípios da aprendizagem colaborativa/cooperativa; utilização de uma rotina definida/sistemática/diária (agenda, calendário anual e mensal, cartazes de identificação dos nomes dos meninos e das meninas do grupo da sala de aula); organização dos espaços da sala e dos recursos (organização em "cantos de atividades" - de literatura, arte, leitura, poesia, entre outros); textualização da sala e exposição dos trabalhos dos alunos; disposição dos materiais de trabalho em sala acessível aos alunos); utilização das diversas linguagens - verbais, matemática, gráfica, plástica e corporal - como ferramentas para a expressão e comunicação de ideais; produção de materiais de suporte para o acesso ao 
conhecimento em sala de aula (tecnologia assistiva), inclusive pelos próprios alunos também, tendo em vista as necessidades específicas dos alunos, entre outros;

- Interação de alunos e de professor com alunos - organização dos tempos e do espaço como promotores de aprendizagem em pares (formação de várias formas de agrupamentos, tendo em vista a criação de zona de desenvolvimento proximal - ZDP: agrupamentos produtivos, em pequenos grupos, duplas, trios ou dependendo dos objetivos da atividade, considerando níveis e/ou centros de interesse, empatia entre as crianças etc.); promoção de atividades simultâneas, mantendo os mesmos objetivos para todos os alunos; e

- Avaliação - instauração de práticas avaliativas baseadas no percurso de aprendizagem de cada aluno (o aluno com deficiência deve ser avaliado em relação ao seu próprio percurso); utilização de variadas formas de registro (relatório dos comportamentos e aprendizagens, portfólio das produções); articulação de tipos distintos de avaliação (individual, coletiva, diagnóstica/interventiva, processual e de produto), entre outros.

Poker (2008) esclarece que o sucesso da escola depende das respostas educativas propostas por ela e, especificamente, pelos professores que atuam diretamente com os alunos. Para a autora, a construção de sistemas educacionais inclusivos deve basear-se na interação com os alunos, ou seja, a partir da identificação das capacidades dos alunos é que será possível organizar objetivos, sequenciar conteúdos, adequando-os aos diferentes ritmos de aprendizagem, utilizar metodologias diferenciadas, avaliar os alunos numa abordagem processual e emancipadora, acompanhando seu desenvolvimento e valorizando seu progresso. "O foco passa a ser a aprendizagem, ou seja, o que cada aluno, diante das condições adequadas de ensino que foram oferecidas, conseguiu aprender" (POKER, 2008, p. 168). Desse modo, as potencialidades de cada aluno são respeitadas e aceitas, valorizando a contribuição de cada um de acordo com suas condições pessoais, e, de forma progressiva e continuada, a escola possibilita o desenvolvimento máximo do aluno considerando suas condições orgânicas, sensoriais, cognitivas, sociais e emocionais.

Nesse contexto, a inclusão subentende um currículo ajustado progressivamente para dar resposta adequada às necessidades educacionais de todos os alunos. Suas características são: flexibilidade, trabalho cooperativo, dinamicidade, uso de recursos alternativos e avaliação contínua, além de focalizar a interação entre as necessidades do educando e as respostas educacionais propiciadas pelo sistema educacional. Essas adequações pressupõem a elaboração de um diagnóstico do contexto familiar e das condições individuais do aluno, para, em um trabalho coletivo e com apoio do serviço pedagógico especializado estruturar as modificações e intervenções nos diferentes âmbitos da ação pedagógica (POKER, 2008). 
Nesse sentido, cada adequação remete a um aluno e suas individualidades, não sendo possível, novamente, prescrever "receitas" de como se trabalhar. Assim, verificamos diferentes iniciativas em cada escola, propostas por um diretor, ou um coordenador, ou um professor, e que vão variar de acordo com as características de cada região, de cada município. Consideramos, portanto, que "cada caso é um caso", e nesse cenário novo que vivenciamos toda experiência traz um novo aprendizado.

Diante de todo o contexto e atores envolvidos na inclusão escolar, focamos nossa atenção ao grupo do AEE, com o propósito de verificar suas percepções sobre o processo e sua atuação.

\section{Metodologia}

Nossa pesquisa caracteriza-se como uma investigação qualitativa (DEMO, 2009) no município de Hortolândia-SP. Participaram da pesquisa as 17 professores de AEE contratadas e em efetivo exercício no município no ano de 2011.

Suas contribuições foram registradas em gravações e posteriormente transcritas, seguindo uma entrevista semiestruturada. As entrevistas foram agendadas previamente com os sujeitos, nas escolas onde atuavam. Utilizamos a análise de conteúdo como método para agrupar as respostas, uma vez que as questões foram abertas. Adotamos a incidência de palavras-chave, abordagem semelhante e conceituação comum como critérios para a formulação das categorias para análise (FRANCO, 2005).

A pesquisa foi submetida e aprovada pelo Comitê de Ética em Pesquisa (CEP) da Faculdade de Ciências Médicas (FCM) da Unicamp, sob o número de processo 0396.0.146.000-09/2009. Os participantes, após receberem as informações referentes à pesquisa, consentiram contribuir para o trabalho assinando o Termo de Consentimento Livre e Esclarecido.

\section{Discussão dos Resultados}

O grupo especialistas em Educação Especial do município de Hortolândia é formado atualmente por 28 professoras. Participaram aquelas que atuam desde 2010, totalizando 17 professoras. Todas têm formação em Pedagogia e pós-graduação Lato Sensu em Educação Especial.

As contribuições das professoras de Educação Especial estão relacionadas ao vínculo que estabelecem com a escola no processo inclusivo. Acreditamos que são elas as responsáveis pelo elo entre ensino especial e comum, uma vez que possuem os conhecimentos 
específicos necessários para atender às necessidades especiais dos alunos e assim auxiliar a comunidade escolar no acolhimento dessas crianças. Assim, selecionamos alguns pontos importantes sobre o trabalho desse grupo: a atuação da especialista, o apoio da escola e a possibilidade de intervenção na inclusão.

\section{A atuação}

A atuação desse grupo no modelo de organização do município acontece por meio de um serviço itinerante, em que as especialistas atuam em 4 ou 5 escolas por semana, realizando o Atendimento Educacional Especializado (AEE). Conforme a maioria das entrevistadas relatou, esse atendimento é realizado individualmente, por 50 minutos, na sala de recursos ou em uma sala destinada para esse fim. Participam do AEE os alunos diagnosticados com alguma deficiência, com laudo de psicólogo, neurologista ou psiquiatra realizado no CIERSaúde ou mesmo em outra instituição.

Algumas professoras $(23,5 \%)$ citaram que, além do AEE, realizam um serviço de apoio aos professores, dando orientações e auxiliando nas adaptações curriculares, como segue no relato:

Então a professora fala assim: "O que eu dou pra ele? Eu tô trabalhando isso, como eu posso incluí-lo nisso?”. Então a gente vai lá e dá uma orientação. Tava trabalhando um projeto e ela tava dando uma interpretação de texto. Lógico que a interpretação, o entendimento dele vai ser diferente, então: "O que você consegue tirar dele, professora? Como você consegue tirar dele? Ele entendeu o que é água, a importância de fechar a torneira, de não lavar a calçada todos os dias"... trazer bem pra realidade dele (Prof. Ed. Especial 1).

Outro grupo $(23,5 \%)$ citou ainda que, além do apoio do AEE aos professores, é dada orientação a pais e funcionários da própria escola.

Conforme descrito no Decreto 6.571/2008 (BRASIL, 2008), o atendimento educacional especializado deve integrar a proposta pedagógica da escola, envolver a participação da família, cujo um de seus objetivos é garantir a transversalidade das ações da educação especial no ensino regular. Portanto, percebemos que a maioria das professoras não engloba em sua atuação a relação com o professor e com a família, definindo seu trabalho como exclusivamente com e para o aluno. A realidade observada também contraria o proposto por Denari (2006) quando salienta uma atuação colaborativa entre o professor de educação especial e o professor do ensino comum, sendo o apoio pedagógico centrado no âmbito da classe comum. 
Segundo Moreira (2006), o ensino itinerante ainda não está plenamente definido na escola comum, sua identidade e importância ainda estão em construção, mesmo para os profissionais que o compõem, ou seja, as professoras especialistas. Apesar de dividir espaço com o ensino comum, são dois sistemas paralelos, e a possibilidade de junção entre ambos aparece em momentos de crise do ensino comum, como solução à falta de respostas do ensino comum.

\section{O apoio da escola}

Sobre o apoio das escolas, professores e alunos, a maioria das especialistas $(64,7 \%)$ afirmou que tanto gestores como professores e alunos são muito receptivos ao trabalho do AEE, o que facilita o processo de inclusão. Esse fato também pode ser verificado nas entrevistas com os diretores e coordenadores, os quais sinalizam o trabalho das professoras especialistas como fator de segurança para a escola, devido aos conhecimentos que apresentam. Destacamos, porém, que esse sentimento de segurança e consequente apoio por parte da gestão escolar e professores não devem se tornar uma transferência de responsabilidade, como alertamos anteriormente.

Mesmo com a satisfação de grande parcela das professoras a respeito do apoio recebido, outro grupo $(23,5 \%)$ citou que, em alguns momentos, percebem uma divisão entre aqueles que apoiam o trabalho e aqueles que não acreditam em seus resultados:

Têm aquelas que acreditam mais, que investem mais, e têm aquelas que estão se adaptando. Uma resistência das professoras, das coordenadoras, a gente não percebe não se tem. Mas fica aquela coisa, né, "Ah, será que vai mesmo?". Fica aquela expectativa. Têm aquelas que te acolhem bem mesmo, acreditam muito na sua ideia... (Prof. Ed. Especial 2).

Quanto aos professores, temos os dois lados: aqueles que trabalham a favor da inclusão, buscando melhores maneiras para realizar o trabalho em sala de aula, trocando ideias com nós, especialistas, pedindo sugestões, enfim, e os que possuem o discurso fatalista dizendo que a inclusão jamais será possível, que o aluno não aprende, que não acompanha a sala de aula, enfim, são aqueles professores que ainda não perceberam que todos os alunos são diferentes, cada qual com suas dificuldades, facilidades, habilidades, enfim, cada um é diferente entre si (Prof. Ed. Especial 4).

Do bloco atendido (três escolas), duas são receptivas, acolhedoras $e$ apoiam os trabalhos desenvolvidos, assim como seus professores. $O$ mesmo apoio não é encontrado na $3 .^{a}$ escola, que é muito resistente à inclusão, desde a gestão até o corpo docente, dificultando bastante o trabalho de inclusão na escola (Prof. Ed. Especial 5).

Acreditamos que essa falta de apoio está diretamente relacionada com a representação da deficiência, como também constatou Martins (2006). O autor verificou a prevalência de 
uma representação descrente e desfavorável dos professores em relação à inclusão escolar de crianças com deficiência, pois predomina entre eles uma concepção de deficiência fortemente representada pela concepção biológica, que remete à questão da deficiência como um problema individual do aluno. Somado a isso, os professores assumem seu papel dentro de uma tendência liberal tradicional, que fundamenta seus pressupostos com base no desenvolvimento individual.

Segundo o autor citado, essas representações que permeiam o universo escolar podem comprometer a inclusão do aluno com deficiência, por serem negativas com relação ao desenvolvimento e ao desempenho do aluno "diferente". Nessa visão, o trabalho das professoras especialistas fica comprometido, uma vez que é considerado desnecessário e sem utilidade.

Os relatos de três professoras $(17,6 \%)$ possibilitam-nos inferir sobre essa questão, pois elas não deram uma resposta direta a respeito do apoio da escola ao seu trabalho. Diante da postura assumida, observamos que a falta de objetividade na resposta refere-se, possivelmente, à ausência de suporte por parte de gestores e professores para seu trabalho.

\section{A possibilidade de intervenção}

Perguntadas sobre sua interferência no processo de inclusão, a maioria das professoras $(82,3 \%)$ afirma que, com o desenvolvimento do seu trabalho, têm condições de interferir nesse processo, citando principalmente as atividades desenvolvidas com os alunos. Desse grupo três professoras $(17,6 \%)$ citaram que sua interferência se refere também à orientação de todos da comunidade escolar; outras duas citaram a segurança que passam para os demais professores, e ainda o contato com a família.

Novamente, destacamos que as professoras especialistas identificam seu trabalho e, consequentemente, a interferência gerada por ele vinculados apenas ao aluno, esquecendo que o AEE é mais abrangente.

No entanto, três delas $(17,6 \%)$ levantaram um ponto importante nessa resposta: a interferência não se dá apenas pela professora de Educação Especial.

O trabalho da professora especialista é o de orientar a comunidade escolar em relação a como trabalhar com o aluno com deficiência ... sempre deixando claro que nosso trabalho é complemento à escolarização do aluno com deficiência e não um substituto (Prof. Ed. Especial 3).

Sim, e muito!!! Quando trago possibilidades de mudança no "olhar" sobre esse aluno. Quando chego em uma escola nunca começo um trabalho "pegando" o aluno com deficiência pra mim. Ele não é aluno de "inclusão", isso estigmatiza, então ele não é aluno da professora de 
Educação Especial, ele é aluno da escola, daquela classe, ele é único e, como qualquer aluno, apresenta também suas necessidades... Com certeza o sucesso é obtido se concebermos a ideia de que o trabalho é coletivo, $e$ não do professor da Educação Especial. $O$ aluno tem que ser visto como aluno da escola e sozinho o professor da Educação Especial não consegue garantir a inclusão pois é preciso que todos: gestores, professores, funcionários, estejam engajados neste processo (Prof. Ed. Especial 5).

Para Moreira (2006), essa divisão de responsabilidade é um ponto crucial na efetivação da inclusão, pois ainda há problemas de interpretação da função do ensino itinerante. Em sua pesquisa, a autora constatou que as professoras do ensino comum avaliam que os alunos são de responsabilidade da professora de educação especial. A postura dinâmica dessa professora, que atende os alunos, organiza materiais, indica recursos, oferece dicas de como trabalhar na sala de aula, acarretou uma postura passiva do professor de sala perante a educação desse aluno.

\section{Considerações finais}

Assim, sobre a função e intervenção dessas profissionais, pudemos verificar que fazem parte do modelo de trabalho de inclusão do município, porém ainda consideram sua atuação mais vinculada ao aluno do que com toda a comunidade escolar, diferente do que prevê o Decreto 7611 de 17 de novembro de 2011, referente ao AEE, que em seu Artigo $2^{\text {o }} \S 1$. $^{\text {e }} \S$ 2. ${ }^{\circ}$ o define como conjunto de atividades, recursos de acessibilidade e pedagógicos organizados institucionalmente, prestado de forma complementar ou suplementar à formação dos alunos no ensino regular, e que deve integrar a proposta pedagógica da escola, envolver a participação da família e ser realizado em articulação com as demais políticas públicas.

Além disso, as professoras especialistas mostram-se satisfeitas com o apoio recebido da gestão escolar, professores e alunos para desenvolver seu trabalho que, segundo elas, interfere no processo de inclusão, pois possibilita um maior desenvolvimento escolar dos alunos com deficiência. Evidenciamos, a seguir, os aspectos relevantes das entrevistas com esse grupo:

Quadro 1 - Pontos relevantes apresentados pelas especialistas

\begin{tabular}{|c|}
\hline Atuação vinculada ao aluno \\
\hline Segurança aos professores \\
\hline Apoio de todos os profissionais da escola \\
\hline
\end{tabular}

Fonte: Filus (2011).

Salientamos que outros aspectos precisam ser levados em conta, principalmente a falta de apoio de algumas unidades escolares relativa à forma como representam a pessoa com 
deficiência; e ainda a divisão de responsabilidades na interferência sobre o processo de inclusão, que não deve ser visto apenas como tarefa da professora especialista, mas de toda a comunidade escolar.

Situamos o discurso das professoras especialistas fortemente ligado à questão psicopedagógica, pois consideram sua atuação mais voltada ao atendimento individualizado do aluno, a fim de melhorar seu desempenho escolar. A própria organização do município permitiu a incorporação dessa função, visto que o atendimento é realizado individualmente, em local separado, com o objetivo, portanto, de levar até o aluno aquilo que ele teria na escola especial.

O ideal seria que esse profissional estivesse na sala de aula, auxiliando o professor para que as atividades se realizassem efetivamente como inclusivas, e não que fizesse um trabalho à parte como tem acontecido. O trabalho individualizado com o objetivo de que os deficientes produzam tanto quanto os "normais" vai ao encontro da ideologia dominante imposta à sociedade, mais uma vez soando os direitos humanos, mas agindo com o objetivo de que os anormais não sejam parasitas (JANNUZZI, 2004), mas produtivos ao sistema econômico.

Concluímos assim que o grupo de profissionais do AEE e a escola necessitam rever sua atuação a fim de que esta se torne mais ampla e possa auxiliar não apenas pontualmente o aluno, mas também trazer informações e novas reflexões aos professores regentes de sala. Sugerimos investigações do contexto atual das escolas, aprofundando nas metodologias utilizadas pelo AEE, a interação entre o AEE e os demais profissionais da escola e demais situações decorrentes dessa atuação, a fim de auxiliar no processo de construção de uma educação realmente inclusiva.

\section{REFERÊNCIAS}

ANTUNES, R. A. Inclusão escolar na pré-escola: o acesso ao currículo. 2008. 164f. Dissertação (Mestrado em Educação) - Faculdade de Educação, Universidade de São Paulo, São Paulo, 2008.

BRASIL. Ministério da Educação. Secretaria de Educação Especial. Estratégias para a educação de alunos com necessidades educacionais especiais. Brasília: MEC/SEESP, 2003. Disponível em: http://portal.mec.gov.br/seesp/arquivos/pdf/serie4.pdf. Acesso em: 10 maio 2010.

BRASIL. Decreto n. ${ }^{\circ}$ 6.571, 17 de setembro de 2008. 2008. Disponível em: http://www.planalto.gov.br/ccivil_03/_Ato2007-2010/2008/Decreto/D6571.htm. Acesso em: 20 maio 2010. 
BRIANT, M. E. P. A inclusão das crianças com deficiência na escola regular na região do Butantã: conhecendo estratégias e ações. 2008. 208f. Dissertação (Mestrado em Ciências) Faculdade de Medicina, Universidade de São Paulo, São Paulo, 2008.

CARVALHO, R. E. Removendo barreiras para a aprendizagem: educação inclusiva. Porto Alegre: Mediação, 2000.

D’ÁGUA, S. V. N. L. Inclusão de alunos com necessidades educacionais na rede regular de ensino: análise da experiência da diretoria de ensino regional de Franca: desafios e possibilidades. 2007. 149f. Tese (Doutorado em Educação e Currículo) - Pontifícia Universidade Católica de São Paulo, São Paulo, 2007.

DEL-MASSO, M. C. S.; ARAÚJO, R. C. T. Atribuições de gravidade à deficiência física em função da extensão dos acometimentos e do contexto escolar. In: OMOTE, S.; GIROTO, C. R. M.; OLIVEIRA, A. A. S. (Org.) Inclusão escolar: as contribuições da educação especial. Marília: Cultura Acadêmica Editora e Fundepe Editora, 2008. p. 65-78.

DEMO, P. A nova LDB: ranços e avanços. 11. ed. Campinas: Papirus, 1997.

DEMO, P. Metodologia do conhecimento científico. São Paulo: Atlas, 2009.

DENARI, F. Um (novo) olhar sobre a formação do professor de educação especial: da segregação à inclusão. In: RODRIGUES, D. (Org.). Inclusão e educação: doze olhares sobre a educação inclusiva. São Paulo: Summus, 2006. p. 35-63.

FILUS, J. F. Amarrações e arrumações na inclusão escolar do município de HortolândiaSP. 2011. 199f. Tese (Doutorado em Educação Física) - Faculdade de Educação Física, Universidade Estadual de Campinas, Campinas, 2011.

FRANCO, M. L. P. B. Análise de conteúdo. 3. ed. Brasília: Líber Livro, 2008.

GARCEZ, L. Da construção de uma ambiência inclusiva no espaço escolar. 2004. 170f. Dissertação (Mestrado em Educação) - Faculdade de Educação, Universidade de São Paulo, São Paulo, 2004.

JANNUZZI, G. M. A educação do deficiente no Brasil: dos primóridos ao início do século XXI. Campinas: Autores Associados, 2004.

LUIZ, F. M. R. Experiências de famílias de crianças com Síndrome de Down no processo de inclusão na rede regular de ensino. 2009. 116f. Dissertação (Mestrado de Enfermagem em Saúde Pública) - Escola de Enfermagem de Ribeirão Preto da Universidade de São Paulo, Ribeirão Preto, 2009.

LUSTOSA, F. G. Inclusão, o olhar que ensina: o movimento da mudança e da transformação das práticas pedagógicas no contexto de uma pesquisa-ação colaborativa. 2009. 295f. Tese (Doutorado em Educação Brasileira) - Pós-graduação em Educação Brasileira, Universidade Federal do Ceará, Ceará, 2009.

MANTOAN, M. T. E. O direito à diferença nas escolas: questões sobre a inclusão escolar de pessoas com e sem deficiência. Revista de Educação Especial, n. 23, p. 17-23, 2004. 
MARTINS, A. E. M. Representações de docentes sobre a inclusão escolar de alunos com deficiência na rede municipal de ensino. 2006. 149f. Dissertação (Mestrado em Psicologia) - Faculdade de Ciências e Letras de Assis, Unesp, Assis, 2006.

MOREIRA, M. H. B. Uma análise do serviço itinerante de apoio pedagógico à inclusão escolar na rede municipal de Araraquara. 2006. 221f. Dissertação (Mestrado em Educação Escolar) - Faculdade de Ciências e Letras da Universidade Estadual Paulista Campus de Araraquara, Araraquara, 2006.

OLIVEIRA, A. A. S. Adequações curriculares na área da deficiência intelectual: algumas reflexões. In: OLIVEIRA, A. A. S.; OMOTE, S.; GIROTO, C. R. M. (Org.). Inclusão escolar: as contribuições da Educação Especial. São Paulo: Cultura Acadêmica Editora e Fundepe Editora, 2008a. p. 129-154.

OLIVEIRA, A. A. S. Currículos e programas na área da Deficiência Intelectual. In: OLIVEIRA, A. A. S.; OMOTE, S.; GIROTO, C. R. M. (Org.). Inclusão escolar: as contribuições da Educação Especial. São Paulo: Cultura Acadêmica Editora e Fundepe Editora, 2008b. p. 111-127.

OLIVEIRA, F. I. W.; PROFETA, M. S. Educação inclusiva e alunos com necessidades educacionais especiais. In: OLIVEIRA, A. A. S.; OMOTE, S.; GIROTO, C. R. M. (Org.). Inclusão escolar: as contribuições da Educação Especial. São Paulo: Cultura Acadêmica Editora e Fundepe Editora, 2008.

OMOTE, S. Diversidade, educação e sociedade inclusiva. In: OLIVEIRA, A. A. S.; OMOTE, S.; GIROTO, C. R. M. (Org.). Inclusão escolar: as contribuições da Educação Especial. São Paulo: Cultura Acadêmica Editora e Fundepe Editora, 2008. p. 15-32.

POKER, R. B. Adequações curriculares na área da surdez. In: OLIVEIRA, A. A. S.; OMOTE, S.; GIROTO, C. R. M. (Org.). Inclusão escolar: as contribuições da Educação Especial. São Paulo: Cultura Acadêmica Editora e Fundepe Editora, 2008. p. 167-178.

RIBEIRO, M.A. "Design Universal” In: CAVALCANTI, A.; GALVÃO, C. Terapia Ocupacional: Fundamentação e Prática. Rio de Janeiro: Guanabara Koogan, 2007

TOMASINI, M. E. A. Expatriação social e a segregação institucional da diferença: reflexões. In: BIANCHETTI, L.; FREIRE, I. M. (Org.). Um olhar sobre a diferença: interação, trabalho e cidadania. 4. ed. Campinas: Papirus, 1998. p. 111-133.

\section{Como referenciar este artigo}

FILUS DE FREITAS, Josiane Fujisawa; FERREIRA DE ARAÚJO, Paulo. A percepção do professor do atendimento educacional especializado sobre seu papel na inclusão escolar. Doxa: Rev. Bras. Psico. e Educ., Araraquara, v. 21, n. 2, p. 387-407, jul./dez. 2019. e-ISSN: 2594-8385. DOI: https://doi.org/10.30715/doxa.v21i2.13185

Submetido em: 20/02/2019

Aprovado em: 20/02/2019

Publicado em: 01/08/2019 